Ind. Health, 1973, 11, 105.

\title{
A METHOD FOR SEPARATION AND DETERMINATION OF URINARY ADRENALINE AND NORADRENALINE
}

\author{
Ayako KOJIMA-SUDO \\ National Institute of Industrial Health, Kizuki-Sumiyoshi, Nakahara-ku, Kawasaki
}

(Received June 30, 1973)

\begin{abstract}
Adrenaline and noradrenaline in alumina extract of human urine were measured with an ion exchange chromatography and an automated fluorometric determination. A few ng of adrenaline was detected by this method. The recoveries of adrenaline and noradrenaline added to alumina extract of urine were 83 and $96 \%$, respectively. It was shown that some compounds in alumina extract of urine interfere with the differential fluorometric method for the determination of catecholamines widely used, but there was recognized almost no interference in this chromatographic method. Therefore, the present method is considered to give more accurate values of urinary adrenaline and noradrenaline than the differential fluorometric method.
\end{abstract}

For the separation of catecholamines, several kinds of chromatographic methods have been reported ${ }^{1 \sim 3}$. Among these methods, the ion exchange chromatography of Kirshner et $a l .^{3)}$ seems to be most useful for the separation of adrenaline and noradrenaline in alumina extract of urine. In the Kirshner's method, however, a large amount of catecholamine, at least $20 \mu \mathrm{g}$, is required, because the amine is separated by coarse particles of resin and determined by colorimetric method.

This paper refers to a procedure for separation of small amounts of adrenaline and noradrenaline, such as $10 \mathrm{ng}$, in alumina eluate of human urine by the use of fine resin and a fluorometric determination method.

\section{EXPERIMENTAL}

\section{Materials}

L-Adrenaline and alumina were obtained from Merck, Germany, L-noradrenaline bitartrate from Koch-Light Laboratory, England, DL-isoproterenol $\mathrm{HCl}$ from Sigma Chemical Company, USA, dopamine $\mathrm{HCl}$ and $\mathrm{DL}$-dopa $\mathrm{HCl}$ from Nutritional Biochemical Corporation, USA, and Amberlite CG-50 type III from Rohm and Haas Company, USA. The other chemical reagents employed in this experiment were purchased from Wako Pure Chemical Industry, Japan. A Technicon AutoAnalyzer and a Turner fluorometer were used for the automated analysis of catecholamines.

\section{Preparation of resin}

Amberlite CG-50 type III (400 to 600 mesh) was washed and cycled through 


\section{A. KOJIMA-SUDO}

the sodium and acid forms. The resin was buffered at $\mathrm{pH} 6.1$, filtered and dried in air as described by Kirshner et al. . $^{3}$ )

\section{Column preparation and operation}

Glass tube of $6 \mathrm{~mm}$ in diameter and $120 \mathrm{~mm}$ in length was used as the column. The bottom of the tube was stopped with a Tygon tube filled with a small amount of glass wool.

Dried resin was stirred with about 2 volumes of $0.2 \mathrm{M}$ ammonium acetate $(\mathrm{pH}$ 6.1) and poured into the column. The height of the resin was adjusted to $8 \mathrm{~cm}$. This preparation was carried out several hours before the column operation, because it was found that the chromatography by the column a few days after preparation resulted in low recovery and imcomplete separation. The $\mathrm{pH}$ of the sample solution was adjusted to 6.1 with diluted aqueous ammonia and 0.1 to 0.2 $\mathrm{ml}$ was placed on the column. After 0.1 to $0.2 \mathrm{ml}$ of $0.2 \mathrm{M}$ ammonium acetate buffer ( $\mathrm{pH}$ 6.1) was added to wash the column, the column was eluted with $0.4 \mathrm{M}$ ammonium acetate buffer ( $\mathrm{pH} \mathrm{5.0)}$ avoiding the stir of resin particle, as seen in Fig. 1. The flow rate was $0.1 \mathrm{ml} / \mathrm{min}$.

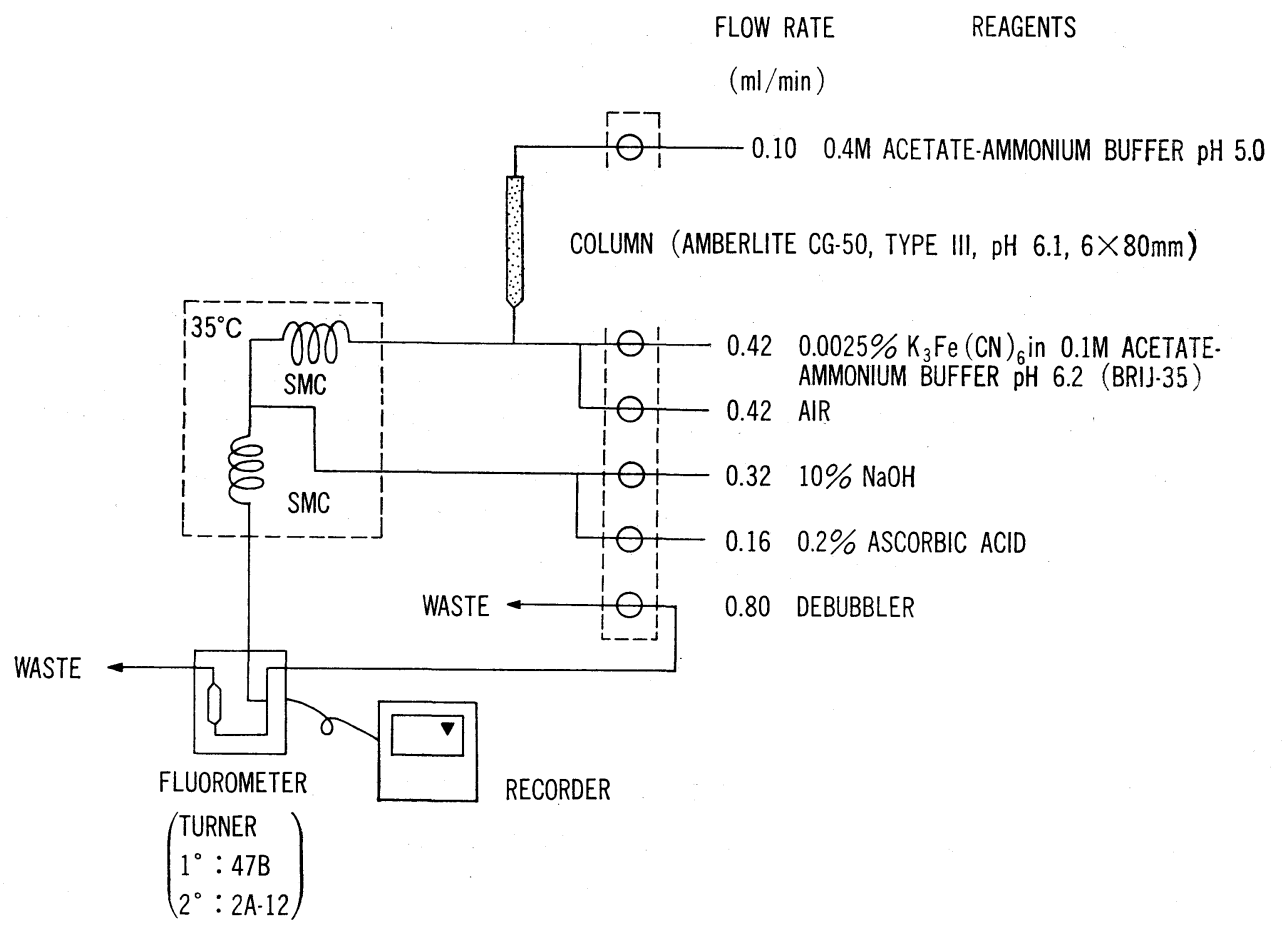

Fig. 1. Flow diagram for separation and determination of adrenaline and noradrenaline in alumina extract of urine.

SMC: Single Mixing Coil

\section{Preparation of urine extract}

Catecholamines in urine were purified with alumina by the method of Euler 


\section{SEPARATION OF URINARY CATECHOLAMINES}

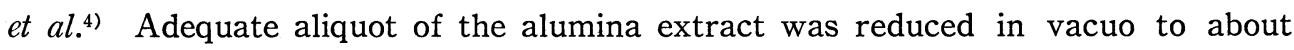
$0.2 \mathrm{ml}$ by a rotary evaporater, below $45^{\circ} \mathrm{C}$. In this procedure, concentrated sample should not be dry, as catecholamines may be changed in dryness. This sample was adjusted to $\mathrm{pH} 6.1$ and placed on the column, as described previously.

Determination of adrenaline and noradrenaline

The amounts of catecholamines in the resin eluate were determined by the trihydroxyindole method, as in Fig. 1, and the fluorescence intensity was recorded continuously (Fig. 2). Adrenaline and noradrenaline contents were calculated as follows ;

(peak width at half-height $) \times($ peak height $) \times($ flow rate of elution $)$

(reading per ng of each amine $) \times($ chart speed $)$

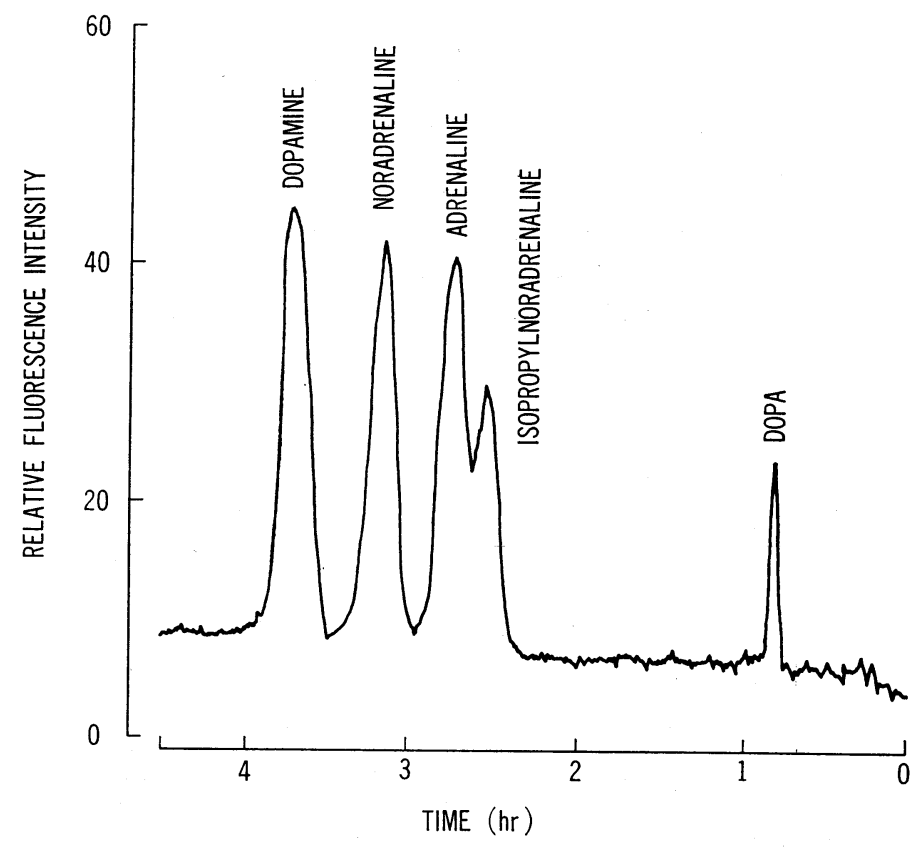

Fig. 2. Chromatogram of aqueous solution of catecholamines.

\section{RESULTS}

Effects of $p H$ of oxidation reaction and of concentration of oxidizing agent on fluorescence intensities of catecholamines

The flow diagram for catecholamine determination was settled as in Fig. 1, in which the flow rate of each reagent and the length of mixing coil in each reaction are about one fourth of those in the automated method ${ }^{5)}$ previously reported. The $\mathrm{pH}$ of catecholamine oxidation is 5.25 in the present method, which is considred to be almost suitable because the fluorescence intensities scarcely change from $\mathrm{pH}$ 5.25 to 6.0 as indicated in Fig. 3. 
A. KOJIMA-SUDO

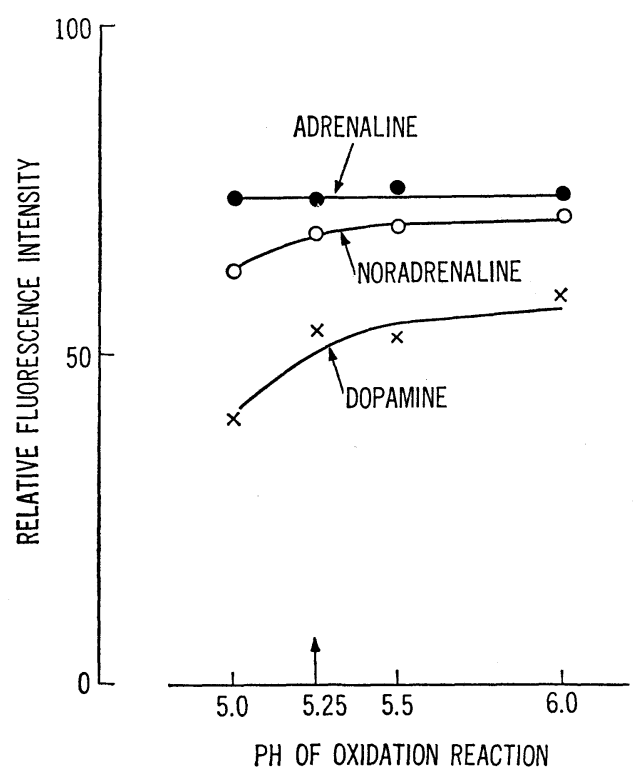

Fig. 3. Effect of $\mathrm{pH}$ of oxidation reaction on fluorescence intensities of catecholamines.
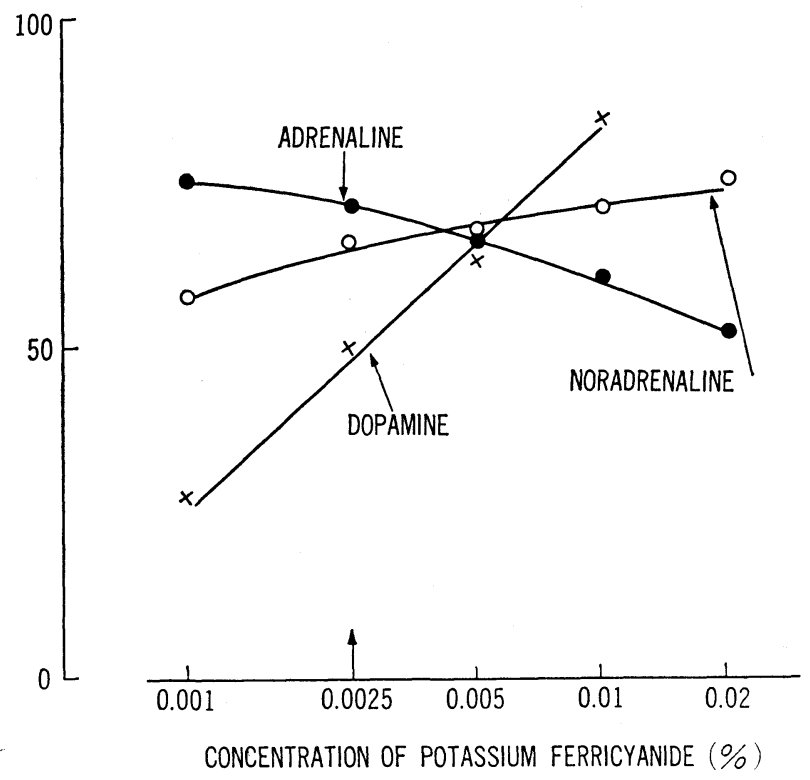

Fig. 4. Effect of concentration of potassium ferricyanide in oxidation reaction on fluorescence intensities of catecholamines. 


\section{SEPARATION OF URINARY CATECHOLAMINES}

The effect of the concentration of potassium ferricyanide on the fluorescence intensities of catecholamines is shown in Fig. 4. From these data, $0.0025 \%$ solution was used in this method, as to be optimal for both adrenaline and noradrenaline.

Use of $0.2 \mathrm{M}$ phosphate buffer $(\mathrm{pH} 7.0)^{6)}$ instead of $0.1 \mathrm{M}$ acetate buffer ( $\mathrm{pH}$ 6.2) in Fig. 1 caused white precipitates during long term operation, which interfered the fluorometry.

\section{Recoveries of adrenaline and noradrenaline in this chromatographic method}

Fig. 2 illustrates the chromatogram of aqueous adrenaline, noradrenaline, isopropylnoradrenaline, dopamine and dopa solution by the procedure described above. As seen in the figure, separation of adrenaline and noradrenaline is complete though separation of adrenaline and isopropylnoradrenaline is not satisfactory. Isopropylnoradrenaline is considered almost not to be contained in normal human urine. The relation between the amounts of added amines to the buffer solution and found ones in this chromatographic procedure is given in Fig. 5. The recoveries of adrenaline (12.5 or $25 \mathrm{ng}$ ) and noradrenaline (25 or $50 \mathrm{ng}$ ) were $83.1 \pm 6.2$ and 93.3 $\pm 7.3 \%$ (mean \pm standard deviation), respectively.

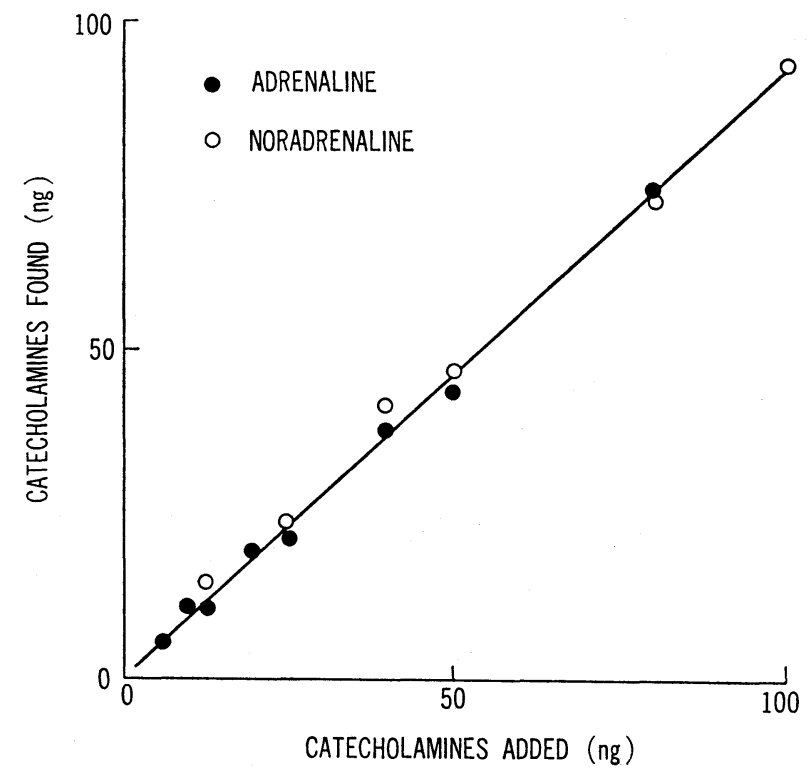

Fig. 5. Calibration curves of adrenaline and noradrenaline in the chromatography only.

Fig. 6 shows the chromatogram of evaporated sample of an alumina extract of normal human urine by the present method. Adrenaline, noradrenaline and dopamine are detected clearly.

The recoveries of catecholamines in human urine was as follows (Table 1). 


\section{A. KOJIMA-SUDO}

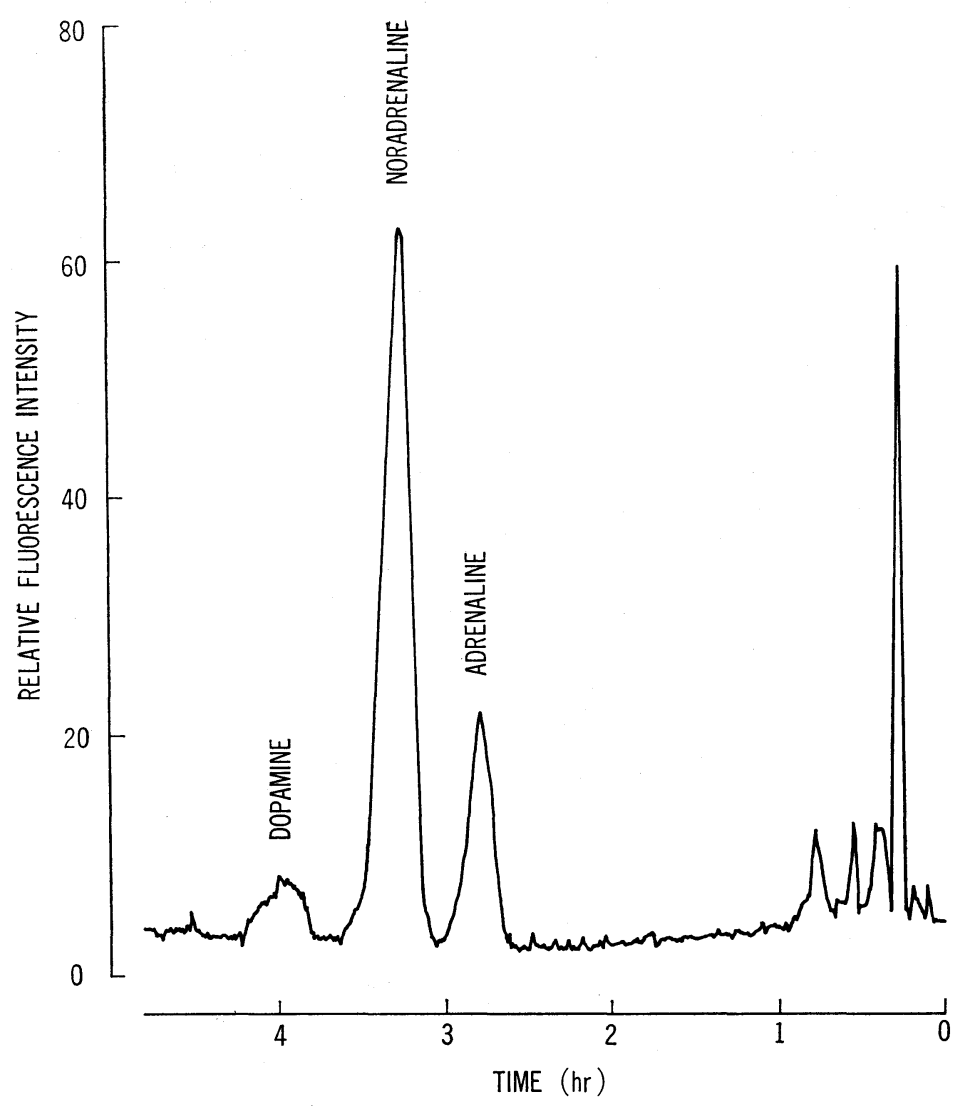

Fig. 6. Chromatogram of an alumina extract of human urine.

Table 1. Reproducibilities and recoveris of adrenaline and noradrenaline in an alumina extract of human urine throughout the evaporation and the chromatography.

(ng, mean \pm standard deviation)

\begin{tabular}{c|c|c|c|c}
\hline \multirow{2}{*}{ Sample } & \multicolumn{2}{|c|}{ Adrenaline } & \multicolumn{2}{c}{ Noradrenaline } \\
\cline { 2 - 5 } & $\begin{array}{c}\text { Evaporate } \\
\text { not to dryness }\end{array}$ & $\begin{array}{c}\text { Evaporate } \\
\text { to dryness }\end{array}$ & $\begin{array}{c}\text { Evaporate } \\
\text { not to dryness }\end{array}$ & $\begin{array}{c}\text { Evaporate } \\
\text { to dryness }\end{array}$ \\
\hline $\begin{array}{c}\text { Alumina extract } \\
\text { of urine 1 ml } \\
\begin{array}{l}\text { Alumina extract } \\
\text { of urine 1 ml } \\
\text { Adrenaline 100 ng } \\
\text { Noradrenaline 200 ng }\end{array}\end{array}$ & $18.5 \pm 1.4$ & $12.1 \pm 0.7$ & $56.2 \pm 3.2$ & $37.1 \pm 4.7$ \\
\hline Recovery & $82.9 \%$ & $74.3 \%$ & $247.3 \pm 11.8$ & $192.8 \pm 13.9$ \\
\hline
\end{tabular}




\section{SEPARATION OF URINARY CATECHOLAMINES}

The amine contents in a normal urine extract was $18.5 \pm 1.4$ for adrenaline and $56.2 \pm 3.2 \mathrm{ng} / \mathrm{ml}$ for noradrenaline (mean \pm standard deviation, $\mathrm{N}=8$ ). To $1 \mathrm{ml}$ of this urine extract $100 \mathrm{ng}$ of adrenaline and $200 \mathrm{ng}$ of noradrenaline were added, and this sample solution was assayed by the present method; the amounts of adrenaline and noradrenaline were $101.4 \pm 5.8$ and $247.3 \pm 11.8 \mathrm{ng} / \mathrm{ml}(\mathrm{N}=5)$, respectively. This indicates that the recovery throughout evaporation and chromatography was 82.9 and $95.6 \%$ for adrenaline and noradrenaline respectively, which was almost equal to the recovery of chromatography only. But, if the sample solution was evaporated to dryness, the recovery considerably decreased.

The catecholamine values in this paper were not corrected for the recovery.

\section{Discussion}

Differential fluorometric measurement after alumina treatment is widely used for catecholamine determination of biological fluids, especially urine. But, the alumina extract of urine seems to contain a considerable amount of interfering substances, and it is almost impossible to measure extremely small quantities of catecholamines accurately. By the present chromatographic method, adrenaline and noradrenaline are measured independently, and even a few ng of adrenaline can be detected.

The recoveries of adrenaline and noradrenaline in the present chromatographic method and the differential fluorometric method ${ }^{6)}$ with or without alumina extraction procedure are summarized in Table 2. The data in the chromatographic method are reasonable if the recovery of alumina extraction is about $80 \%$, and there is almost no difference in the recovery between from aqueous solution and from urine alumina extract. But, in the case of the differential fluorometric method, the recoveries from urine alumina extract are unreasonable because adrenaline and noradrenaline recoveries of alumina extraction are calculated to be 81 and $82 \%$ from aqueous solution while 99 and $67 \%$ from urine alumina extract, respectively. This fact may indicate that there is some substances in alumina extract of urine

Table 2. Recoveries of adrenaline and noradrenaline in the present chromatographic method and in the differential fluorometric method with or without alumina extraction. (mean, \%)

\begin{tabular}{|c|c|c|c|c|c|}
\hline & \multirow{2}{*}{ Procedure } & \multicolumn{2}{|c|}{$\begin{array}{l}\text { Recovery from } \\
\text { aqueous solution }\end{array}$} & \multicolumn{2}{|c|}{ Recovery from urine } \\
\hline & & Adrenaline & Noradrenaline & Adrenaline & Noradrenaline \\
\hline \multirow{2}{*}{$\begin{array}{l}\text { Alumina } \\
\text { extraction }\end{array}$} & Chromatographic method & 60 & 76 & 67 & 75 \\
\hline & Chromatographic method & 83 & 93 & $83^{\dagger}$ & $96 \dagger$ \\
\hline \multirow[t]{2}{*}{$\begin{array}{l}\text { Alumina } \\
\text { extraction }\end{array}$} & $\begin{array}{l}\text { Differential } \\
\quad \text { fluorometric method }\end{array}$ & 81 & 82 & 96 & 58 \\
\hline & $\begin{array}{l}\text { Differential } \\
\text { fluorometric method }\end{array}$ & $(100)$ & $(100)$ & $97^{\dagger}$ & $87^{\dagger}$ \\
\hline
\end{tabular}

$\dagger$ : These values are the recoveries of the amines added to alumina eluate of urine. 


\section{A. KOJIMA-SUDO}

which interfere with the differential fluorometric determination of catecholamines. Therefore, this chromatographic method is considered to give more accurate value of urinary adrenaline and noradrenaline rather than the differential fluorometric method, though the recovery is lower than that in the latter method.

Adrenaline and noradrenaline in 90 samples of alumina eluates of daytime human urines were determined by both of the present chromatographic method and the differential fluorometric method ${ }^{6)}$, and correlation coefficients were very significant $(r=0.968$ for adrenaline and 0.943 for noradrenaline, $p<0.01$ ), but there were recognized some differences between the data of the two methods because the regression lines were $y=0.78 x+1.0$ for adrenaline and $y=0.87 x-3.3$ for noradrenaline ( $\mathrm{y}$ : the present chromatographic method and $\mathrm{x}$ : the differential fluorometric method, $\mathrm{ng} / \mathrm{ml}$ ) if the data were corrected for the recovery of each procedure except alumina extraction. That is, the value of the differential fluorometric method was higher than the value of the chromatographic method. This fact may support the existence of some interfering substances in alumina eluate of urine as described before.

The chromatography by the ion exchange resin is very effective for separation of adrenaline and noradrenaline, and the trihydroxyindole method is very sensitive and specific for these amines. So, the present method is considered to be very useful to determine small amounts of adrenaline and noradrenaline, and by the introduction of finer particle resin and of micropump it will be able to measure picogram of the amines.

\section{REFERENCES}

1) Häggendal, J. (1962). Scand. J. Clin. Lab. Invest., 14, 537.

2) Karoum, F., Cattabeni, F., Costa, E., Ruthven, C. R. J. and Sandler, M. (1972). Anal. Biochem., 47, 550 .

3) Kirshner, N. and Goodall, McC. (1957). J. Biol. Chem., 226, 207.

4) Euler, U.S. von and Lishajko, F. (1961). Acta Physiol. Scand., 51, 348.

5) Kojima, A. (1966). Ind. Health, 4, 98.

6) Kojima-Sudo, A. (1973). Ind. Health, 11, 66. 